\title{
PREFERENSI PRIVASI VISUAL PADA RUANG KERJA TIM REDAKSI KANTOR PUSAT SURAT KABAR PIKIRAN RAKYAT BANDUNG
}

\author{
Hafizha Azka, Yunita Setyoningrum, Ferlina Sugata \\ (Email: hafizhaichaazka@gmail.com) \\ Desain Interior \\ Fakultas Seni Rupa dan Desain \\ Universitas Kristen Maranatha \\ Jl. Prof.drg. Suria Sumantri, MPH no. 65, Bandung, Indonesia
}

\begin{abstract}
ABSTRAK
Penelitian ini mengeksplorasi bagaimana setting interior ruang kerja terbuka (open-plan) di kantor pusat Pikiran Rakyat Bandung mempengaruhi preferensi privasi visual karyawan tim redaksi. Tujuannya adalah untuk mengetahui privasi visual seperti apa yang dibutuhkan karyawan dan kondisi setting interior ruang kerja seperti apa yang dapat mengganggu privasi visual karyawan pada ruang kantor terbuka. Area kerja yang diteliti adalah area yang diduga memiliki potensi gangguan privasi visual, yaitu area kerja yang: a) membelakangi sirkulasi, b) berada di persimpangan sirkulasi, c) berbatasan langsung dengan pintu, d) berdekatan dengan fasilitas kerja bersama, e) berhadapan dengan rekan kerja, dan f) berdekatan dengan rekan kerja di samping kanan atau kiri. Metode penelitian yang digunakan adalah kualitatif deskriptif dengan teknik pengumpulan data studi lapangan, yang terdiri atas observasi lapangan dan wawancara. Hasil penelitian menunjukkan bahwa: a) Setting interior ruang kerja pada ruang kantor terbuka yang berdekatan dengan rekan kerja baik di samping kanan maupun di samping kiri menjadi faktor paling dominan yang menyebabkan gangguan pada karyawan dalam privasi visual; b) Karakteristik pekerjaan (task) dengan kebutuhan untuk menyendiri (solitude) mempengaruhi preferensi privasi visual karyawan, khususnya pada tata letak pekerjaan (monitor). Dengan demikian, perencanaan ruang kantor pada ruang kantor terbuka di kantor pusat Pikiran Rakyat Bandung sebaiknya mempertimbangkan kebutuhan privasi dengan cara: 1) Pengaturan ulang pada setting interior ruang kerja dengan jumlah ruang kerja yang ideal, 2) Adanya pembatas fisik antar ruang kerja, dan 3) Pemusatan fasilitas kerja bersama untuk para karyawan dalam ruang kantor terbuka agar aktivitasnya tidak mengganggu area kerja yang lainnya.
\end{abstract}

Kata kunci: area kerja; kantor terbuka; privasi visual; setting interior

\begin{abstract}
This research explores how the open-plan office space in the Pikiran Rakyat Bandung head officeinfluences the visual privacy preferences of the editorial staff. The aim is to find out what visual privacy is needed by the employees and the factors that might cause visual privacy disturbance on the employees of the open-plan office. The research observed several workstations with the potential of visual privacy disturbances, namely workstations that: a) is back-to-back with the walkway, b) is located at a walkway junction, $c$ ) is directly adjacent to the door, $d$ ) is adjacent to joint work facilities, e) is facing other coworkers, and $f$ ) is close to other co-workers on the right or left side. The research method was descriptive qualitative, using field observations and interviews to collect data. The result shows that: a) The interior settings of the workspace in open office space adjacent to coworkers both on the right side and left side are the most dominant factors that cause disruption to employees in visual privacy; b) Characteristics of employee's task which need solitude condition influence visual privacy preferences the most, especially in the work layout (monitor). Thus, office space planning in an open office space at the Bandung People's Mind headquarters should consider the need for visual privacy by: a) Rearranging the interior settings of the workspace with the ideal amount of work space,
\end{abstract}


Serat Rupa Journal of Design, July 2019, Vol.3, No.2: 134-149

E-ISSN: 2477-586X, ISSN: 2338-3348 | https://doi.org/10.28932/srjd.v3i2.1192 | Received: 09-01-2019, Accepted: 25-07-2019 Hafizha Azka, Yunita Setyoningrum, Ferlina Sugata

Preferensi Visual Pada Ruang Kerja Tim Redaksi Kantor Pusat Surat Kabar Pikiran Rakyat Bandung

b) Adding physical barriers between workspaces, and c) Arranging centralized shared work facilities for employees in open office space, hence minimalize disturbance from the conducted activities.

Keywords: interior design setting; open-plan office; visual privacy; working area

\section{PENDAHULUAN}

Ruang kantor terbuka atau open-plan office adalah tata ruang kerja yang berukuran cukup luas ditempati oleh beberapa karyawan untuk bekerja bersama di dalam satu ruang luas termaksud tanpa dipisah oleh pembatas yang permanen. Pada zaman modern ini telah banyak tata ruang kantor yang sengaja didesain terbuka, hal ini bertujuan untuk meningkatkan komunikasi karyawan satu sama lain. Sebuah kantor yang didesain dengan penataan layout yang baik akan mempermudah koordinasi antar divisi guna mengoptimalkan pekerjaan para staf perusahaan (Gregory \& Wiechmann, 1999). Selanjutnya, Kim dan De Dear (2013) menyatakan meskipun lingkungan kerja terbuka mendominasi tempat kerja modern, ada sedikit bukti kuat bahwa lingkungan kerja seperti itu benar-benar meningkatkan interaksi antar rekan kerja (Kim \& de Dear, 2013).

Desain ruang dan fasilitas kerja merupakan salah satu faktor yang mempengaruhi keadaan psikologis karyawan, terutama ketika tata ruang kantor terbuka dan fasilitas kerjanya dianggap tidak memenuhi kebutuhan karyawan. Hal ini termasuk kebutuhan privasi, baik saat bekerja maupun saat beristirahat di ruang kerja. Westin (1976) menyatakan bahwa identifikasi privasi menyangkut pilihan mengenai sejauh mana seseorang mau melakukan kontak langsung dengan orang lain. Westin (1976) juga menyebutkan bahwa pilihan privasi itu dapat digolongkan menjadi keadaan privasi kesendirian, keintiman, anonimitas, dan reserve (Westin dalam Rizza et al., n.d.,2011).

Pikiran Rakyat merupakan surat kabar ternama di Jawa Barat yang diterbitkan di kota Bandung. Perusahaan ini memiliki tiga kantor yang berada di Bandung, yaitu kantor pusat yang berada di Jl. Asia Afrika no.77 dan kantor redaksi yang berada di Jl. Soekarno Hatta no. 147. Namun, pada tanggal 4 Oktober 2014 lalu kantor redaksi mengalami kebakaran yang diakibatkan korsleting listrik sehingga bangunan, perabot, berkas-berkas, dan fasilitas lainnya hangus terbakar sehingga menyebabkan seluruh ruang kerja tim redaksi tidak dapat digunakan lagi. Setelah itu, seluruh tim redaksi dipindahkan ke kantor pusat dengan keadaan yang cukup darurat, adanya dua kali pemindahan hingga ruangan yang sekarang sedang ditempati. 
Serat Rupa Journal of Design, July 2019, Vol.3, No.2: 134-149

E-ISSN: 2477-586X, ISSN: 2338-3348 | https://doi.org/10.28932/srjd.v3i2.1192 | Received: 09-01-2019, Accepted: 25-07-2019 Hafizha Azka, Yunita Setyoningrum, Ferlina Sugata

Preferensi Visual Pada Ruang Kerja Tim Redaksi Kantor Pusat Surat Kabar Pikiran Rakyat Bandung

Karyawan tim redaksi yang menempati ruang kantor terbuka adalah redaktur, asisten redaktur, wartawan dan staf. Luas ruang kerja yang lebih kecil dan kondisi ruang kerja dalam ruang kantor terbuka sekarang tidak memiliki pembatas fisik antar ruang kerja untuk menandakan wilayah pribadi (Zavani \& Rahardjo, 2016). Hal ini menyebabkan terganggunya privasi visual dalam aspek tatap muka, pekerjaan (monitor), dan gangguan lingkungan.

Berdasarkan kondisi tersebut, pertanyaan penelitian ini adalah: (1) Privasi seperti apa yang dibutuhkan karyawan tim redaksi dalam menjalani pekerjaannya di ruang kerja masingmasing dalam ruang kantor terbuka? (2) Apakah setting ruang interior ruang kerja yang dimiliki karyawan sudah mampu menunjang kebutuhan privasi visual dalam aspek tatap muka, pekerjaan dalam monitor, dan gangguan lingkungan? (3) Bagaimana peran setting interior ruang kerja terhadap preferensi privasi visual pada ruang kantor terbuka yang ditempati tim redaksi? Sementara tujuan penelitian ini adalah: (1) Mengetahui privasi visual seperti apa yang dibutuhkan karyawan tim redaksi dalam aspek tatap muka, pekerjaan dalam monitor, dan gangguan lingkungan saat menjalani pekerjaan di ruangan masingmasing; (2) Mengetahui kondisi setting interior ruang kerja seperti apa yang dapat mengganggu privasi visual karyawan pada ruang kerja tim redaksi dalam ruang kantor terbuka.

\section{Privasi}

Privasi sebagai kontrol selektif dari akses pada diri sendiri ataupun kelompok (Altman, 1975), terlepas dari preferensi privasi, perilaku, dan tata nilai, setiap orang bisa mempunyai keragaman harapan akan privasi, bisa rendah bisa tinggi (Edney \& Buda, 1976). Marshall (1966) selanjutnya mengelompokkan privasi menjadi enam jenis privasi, yakni:

a) Keinginan menyendiri (solitude). Privasi dapat diperoleh karena dibatasi oleh elemen tertentu sehingga bebas melakukan apa saja dan bebas dari perhatian orang lain

b) Keinginan menjauh (seclusion) dari pandangan dan gangguan suara tetangga atau kebisingan lalu lintas

c) Keinginan untuk intim dengan orang-orang (intimacy). Misalnya, dengan keluarga atau orang tertentu saja seperti kekasih tetapi jauh dari semua orang lainnya.

d) Keinginan untuk tidak dikenali atau tidak diperhatikan oleh orang lain (anonimity) walaupun sedang berada di tempat umum.

e) Keinginan seseorang untuk tidak terlihat oleh orang lain dengan menambahkan sekat pembatas di sekelilingnya (reserve). 
f) Keinginan untuk tidak terlibat dengan para orang di dekatnya (not neighboring). Pada kondisi ini, seseorang tidak suka berdekatan dengan orang lain.

Jenis privasi solitude, seclusion, dan intimacy menurut Holahan (1982) merupakan golongan yang tidak menginginkan gangguan secara fisik. Sementara itu anonimity, reserve, dan notneighboring merupakan golongan yang ingin menjaga kerahasiaan informasi mengenai dirinya yang kemudian terwujud dalam tingkah lakunya (Holahan dalam Sarwono, 1992).

\section{Ruang Pribadi (Personal Space)}

Ruang pribadi atau yang biasa disebut dengan ruang personal dan teritori merupakan mekanisme ketika orang dapat mengatur privasinya. Ruang pribadi adalah suatu jarak komunikasi dengan jarak antar individu ini adalah juga jarak komunikasi (Hall, 1963). Suatu kondisi yang terjadi ketika ruang pribadi dan teritorial berfungsi tidak baik disebut kesesakan (crowding). Selain itu, kesesakan (crowding) merupakan suatu proses interpersonal pada suatu tingkatan interaksi manusia satu dengan lainnya dalam suatu pasangan atau kelompok kecil (Laurens, 2006)

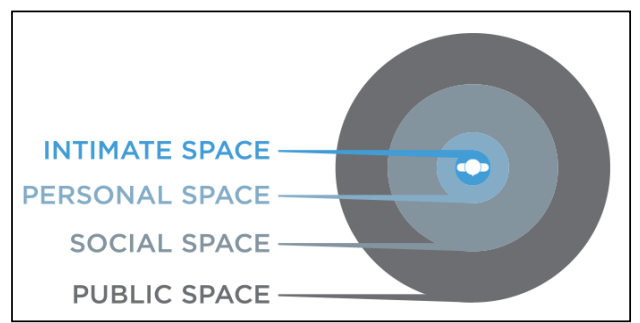

Gambar 1. Ruang Pribadi (Personal Space)

(Sumber: www. Newdealdesign.com, diakses tanggal 1 September 2018)

Edward T. Hall dalam buku "The Hidden Dimension" menjelaskan bahwa terdapat dimensi tersembunyi dari 4 tingkat wilayah komunikasi, yaitu:

a. Ruang Publik (Public Space): Area paling luar dan paling luas, dengan jarak melebihi $350 \mathrm{~cm}$.

b. Ruang Sosial (Sosial Space): Area tempat individu mengharapkan kontak sosial murni dan sementara dengan jarak sosial antara $120-350 \mathrm{~cm}$.

c. Ruang Pribadi (Personal Space): Ruang dengan seseorang kemungkinan besar memilih teman, sahabat, ataupun orang-orang yang sudah dipercaya untuk melakukan percakapan dengan jarak 50-120 cm.

d. Ruang Intim (Intimate Space): Area yang langsung mengelililngi tubuh individu, paling pribadi dan melibatkan interaksi fisik dan emosional dengan jarak 0-50 cm. 
Serat Rupa Journal of Design, July 2019, Vol.3, No.2: 134-149

E-ISSN: 2477-586X, ISSN: 2338-3348 | https://doi.org/10.28932/srjd.v3i2.1192 | Received: 09-01-2019, Accepted: 25-07-2019 Hafizha Azka, Yunita Setyoningrum, Ferlina Sugata

Preferensi Visual Pada Ruang Kerja Tim Redaksi Kantor Pusat Surat Kabar Pikiran Rakyat Bandung

Ruang pribadi dan teritori merupakan alat utama untuk mewujudkan privasi. Hall (1996) mengidentifikasikan dua faktor lain yang mempengaruhi penggunaan proksemik di antaranya:

1. Fitur tetap (Fixed features), memiliki sifat yang tak bergerak atau tidak bisa dipindahkan, seperti tata letak bangunan, ruangan, dinding, pintu dan jendela.

2. Fitur semi-tetap (Semi-fixed features), elemen di dalam ruang yang dapat dipindahkan, seperti furnitur, kursi, meja.

Tata letak tertentu dapat memisahkan orang (sociofugal) atau menyatukan orang-orang (sociopetal) yang merujuk pada studi sebelumnya oleh Osmond (1957) (Osmond dalam Hall, 1966).

\section{Privasi di Dalam Ruang Kerja}

Pengurangan wilayah pribadi, tata letak kantor terbuka sering gagal untuk mengisolasi penghuni dari observasi yang tidak diinginkan (privasi visual), yang dalam keseluruhan perasaan kehilangan privasi dan kontrol pribadi atas ruang kerja mereka (Danielsson \& Bodin, 2009). Penelitian yang dilakukan oleh DeMarco dan Lister (1987) menunjukkan bahwa dibutuhkan sekitar 15 menit untuk mencapai keadaan konsentrasi dan setiap adanya gangguan dibutuhkan waktu 15 menit untuk kembali berkonsentrasi. Oleh karena itu, preferensi, harapan, nilai, dan perilaku seseorang berbeda satu sama lain dan berbeda dari waktu ke waktu karena setiap individu berusaha mendapatkan privasi dalam berbagai tingkatan yang dibutuhkannya. Umumnya dinding dan partisi menyajikan kepekaan privasi yang lebih besar (Sundstrom, Burt, \& Kamp, 1980).

\section{Privasi Visual}

Privasi visual adalah menjaga tingkat kontak sosial optimal yang dibutuhkan setiap orang Dalam ruang kantor terbuka, privasi visual disediakan hanya untuk ruang kerja yang diperlukan untuk melakukan fungsi pekerjaan tertentu dengan menggunakan pembatas fisik seperti panel-panel yang didirikan di ruang kerja tersebut. Privasi visual memiliki dua aspek yaitu:

1. Terlihat oleh rekan kerja dan melihat rekan kerja di kantor. Terlihat oleh rekan kerja menyebabkan pekerja stress karena mereka merasa seperti sedang menonton saat mereka bekerja, terutama oleh atasan mereka atau memiliki rasa berada di akuarium yang dibuat oleh panel kaca interior (Goodrich, 1982).

2. Melihat rekan kerja bekerja di dekat situ. Melihat orang berjalan melewati kantor mereka atau berhenti menyapa pekerja yang terganggu secara visual. Gangguan 
Serat Rupa Journal of Design, July 2019, Vol.3, No.2: 134-149

E-ISSN: 2477-586X, ISSN: 2338-3348 | https://doi.org/10.28932/srjd.v3i2.1192 | Received: 09-01-2019, Accepted: 25-07-2019 Hafizha Azka, Yunita Setyoningrum, Ferlina Sugata

Preferensi Visual Pada Ruang Kerja Tim Redaksi Kantor Pusat Surat Kabar Pikiran Rakyat Bandung

visual dapat menghasilkan hilangnya waktu produksi dan menambah kesalahan (Kupritz, 1998). (Johnson, n.d.,2017).

\section{METODE PENELITIAN}

Penelitian ini menggunakan metode kualitatif deskriptif dengan teknik pengumpulan data berupa studi lapangan yang terdiri dari observasi lapangan dan wawancara. Subjek pada penelitian ini adalah karyawan tim redaksi yang menempati ruang kantor terbuka, lalu objek pada penelitian ini adalah ruang kerja yang ditempati karyawan tim redaksi. Sampel kemudian yang ditentukan dari ruang kantor terbuka terdiri atas 11 orang karyawan (B1B11). Subjek dipilih dengan kondisi setting interior ruang kerja yang diduga menyebabkan gangguan, yaitu area kerja yang: (a) membelakangi sirkulasi; (b) berada di persimpangan sirkulasi; (c) berbatasan langsung dengan pintu; (d) berdekatan dengan fasilitas kerja bersama (fasilitas yang dimaksud adalah lemari arsip dan printer); (e) berhadapan dengan rekan kerja; (f) berdekatan dengan rekan kerja baik di samping kanan maupun di samping kiri. Sementara aspek privasi visual yang diteliti pada penelitian ini terdiri dari: (a) pengendalian terhadap kondisi bertatap muka, memandang, atau dipandang oleh orang lain saat bekerja, (b) pengendalian terhadap kondisi dilihat atau diawasi pekerjaannya (khususnya layar monitor), dan (c) pengendalian terhadap kondisi melihat aktivitas atau kejadian di sekitar yang berpotensi mengganggu konsentrasi kerja (gangguan lingkungan). Setelah dilakukan observasi lapangan, penyebaran kuesioner task list dan kuesioner tertutup kepada responden di ruang kantor terbuka tim redaksi, peneliti melakukan pencocokan data pada kondisi setting interior ruang kerja yang ada sekarang dengan kondisi gangguan yang dirasakan karyawan.

\section{PEMBAHASAN}

Ruang kantor terbuka ditempati oleh tim redaksi karyawan yang terdiri dari redaktur, asisten redaktur, wartawan, dan staff. Selain itu ada sebagian karyawan tim produksi yang menempati ruangan ini. 
Serat Rupa Journal of Design, July 2019, Vol.3, No.2: 134-149

E-ISSN: 2477-586X, ISSN: 2338-3348 | https://doi.org/10.28932/srjd.v3i2.1192 | Received: 09-01-2019, Accepted: 25-07-2019

Hafizha Azka, Yunita Setyoningrum, Ferlina Sugata

Preferensi Visual Pada Ruang Kerja Tim Redaksi Kantor Pusat Surat Kabar Pikiran Rakyat Bandung

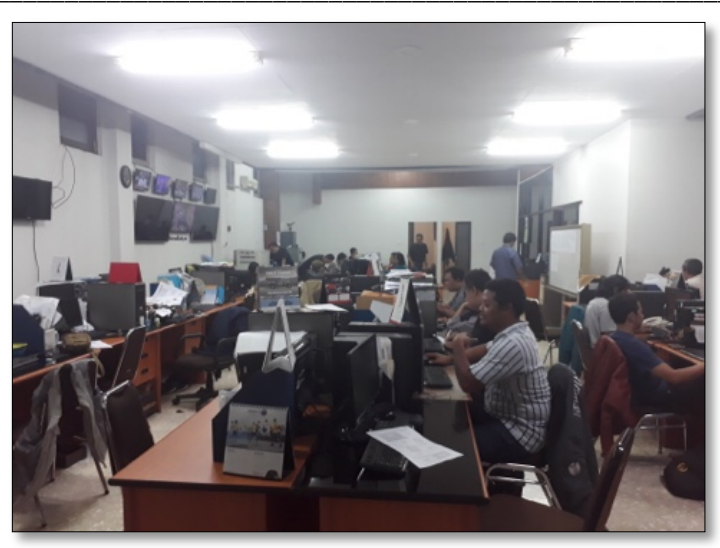

Gambar 2. Ruang kantor terbuka tim redaksi (Sumber: Data Pribadi, 2018)

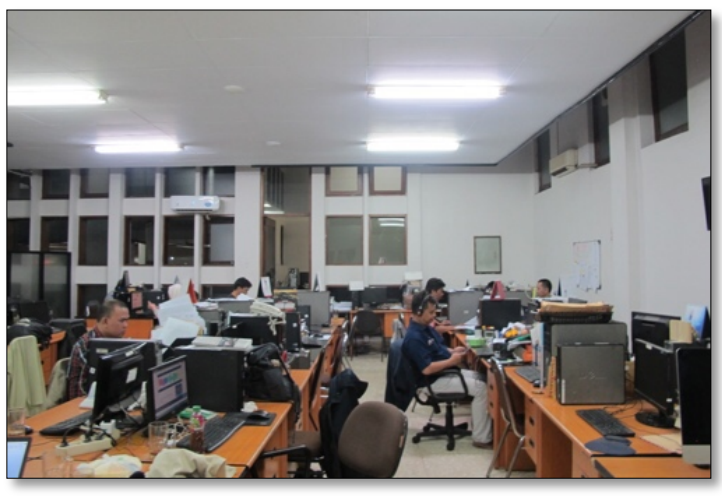

Gambar 3. Ruang kantor terbuka tim redaksi (Sumber: Data Pribadi, 2018)

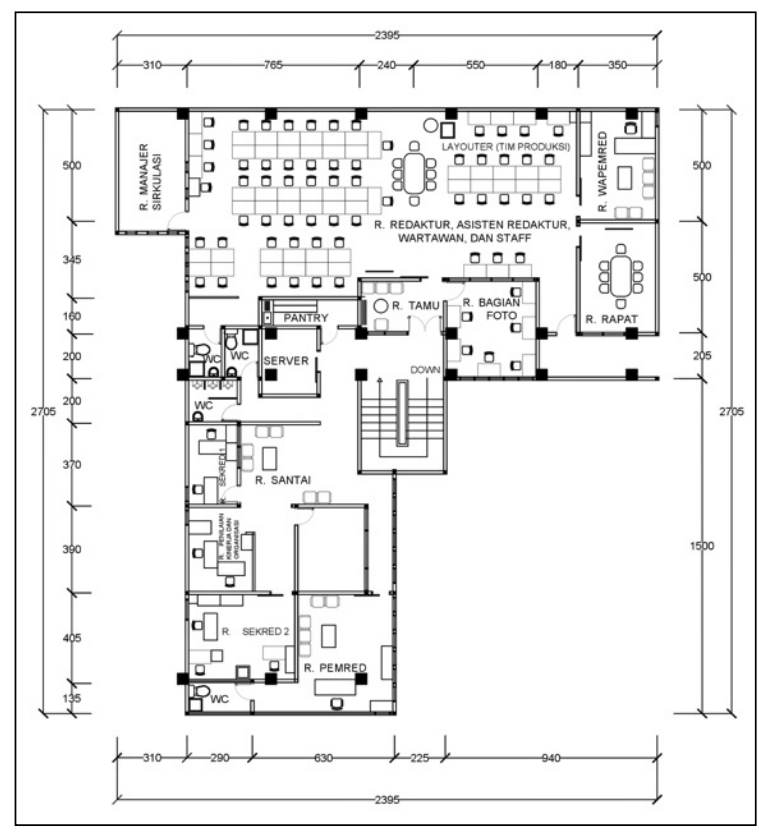

Gambar 4. Denah ruang kerja tim redaksi (Sumber: Bagian Umum Pikiran Rakyat) 
Serat Rupa Journal of Design, July 2019, Vol.3, No.2: 134-149

E-ISSN: 2477-586X, ISSN: 2338-3348 | https://doi.org/10.28932/srjd.v3i2.1192 | Received: 09-01-2019, Accepted: 25-07-2019 Hafizha Azka, Yunita Setyoningrum, Ferlina Sugata

Preferensi Visual Pada Ruang Kerja Tim Redaksi Kantor Pusat Surat Kabar Pikiran Rakyat Bandung

\section{Redaktur Pelaksana (B1)}

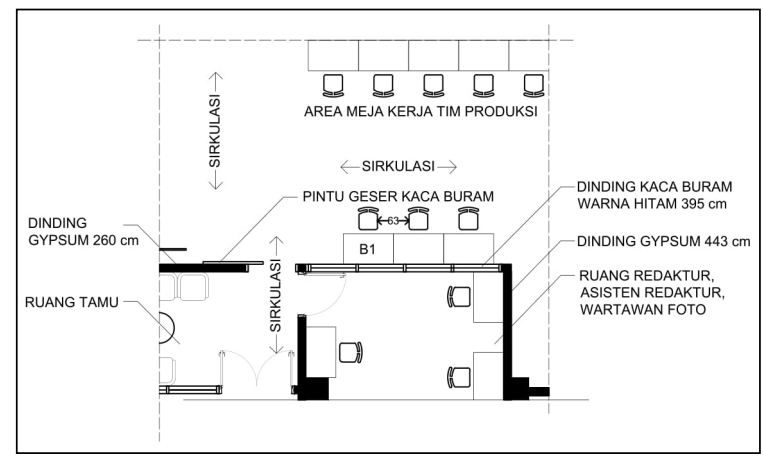

Gambar 5.Setting interior ruang kerja Redaktur Pelaksana (B1) (Sumber: Data Pribadi, 2018)

2. Asisten Redaktur Olahraga (B2)

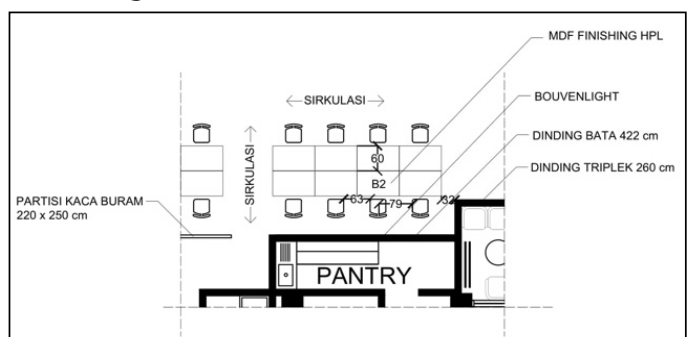

Gambar 6. Setting interior ruang kerja Asisten Redaktur Olahraga (B2) (Sumber: Data Pribadi, 2018)

3. Kasie Dokumentasi (B3)

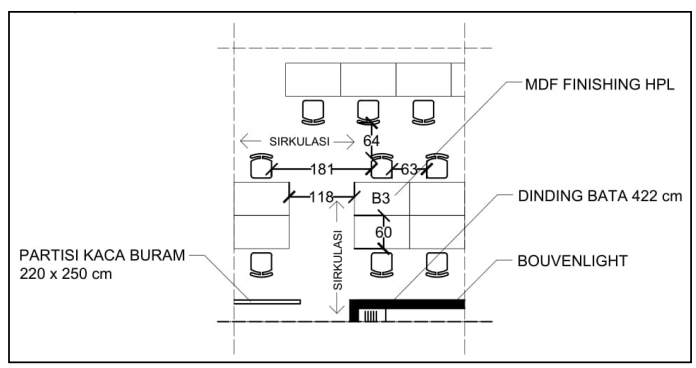

Gambar 7. Setting interior ruang kerja Kasie Dokumentasi (B3)

(Sumber: Data Pribadi, 2018)

\section{Asisten Redaktur Dalam Negeri (B4)}

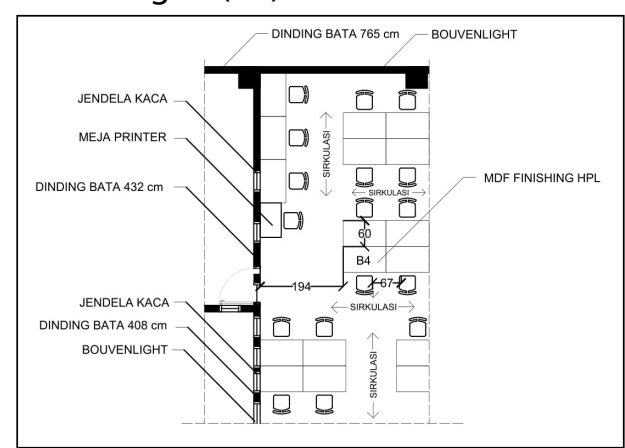

Gambar 8. Setting interior ruang kerja Asisten Redaktur Dalam Negeri (B4) (Sumber: Data Pribadi, 2018) 
Serat Rupa Journal of Design, July 2019, Vol.3, No.2: 134-149

E-ISSN: 2477-586X, ISSN: 2338-3348 | https://doi.org/10.28932/srjd.v3i2.1192 | Received: 09-01-2019, Accepted: 25-07-2019 Hafizha Azka, Yunita Setyoningrum, Ferlina Sugata

Preferensi Visual Pada Ruang Kerja Tim Redaksi Kantor Pusat Surat Kabar Pikiran Rakyat Bandung

\section{Redaktur Bandung Raya (B5)}

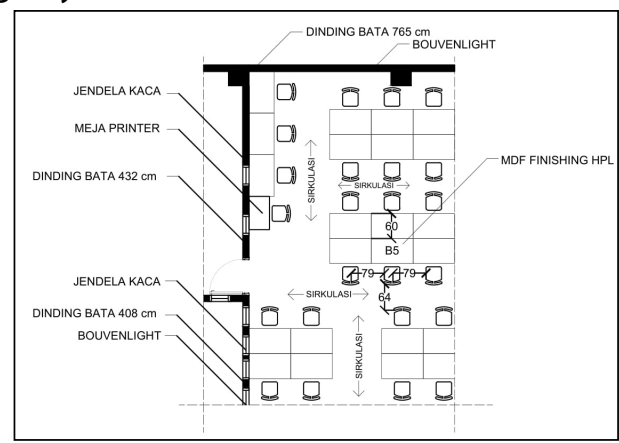

Gambar 9.Setting interior ruang kerja Redaktur Bandung Raya (B5) (Sumber: Data Pribadi, 2018)

\section{Staff Reset (B6)}

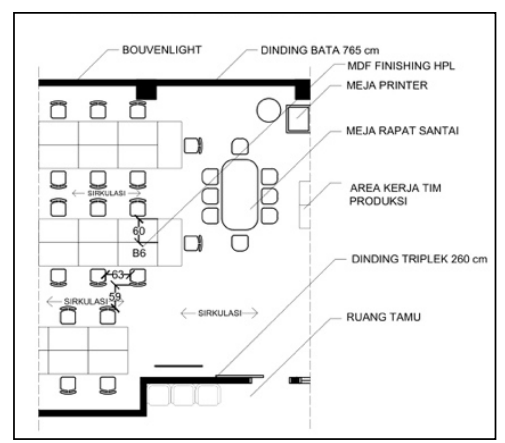

Gambar 10. Setting interior ruang kerja Staff Reset (B6) (Sumber: Data Pribadi, 2018)

7. Kasie Dokumentasi (B7)

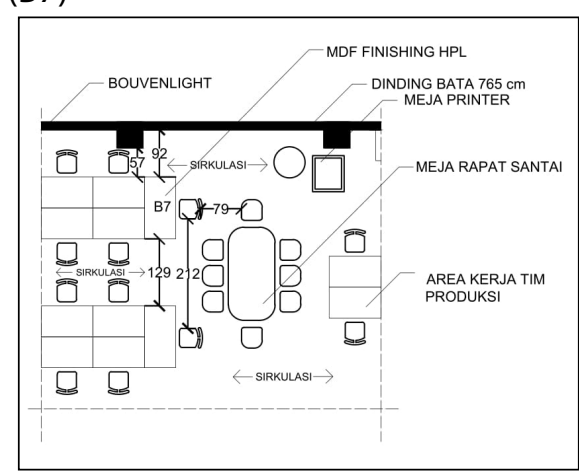

Gambar 11. Setting interior ruang kerja Kasie Dokumentasi (B7) (Sumber: Data Pribadi, 2018)

8. Redaktur Jawa Barat (B8)

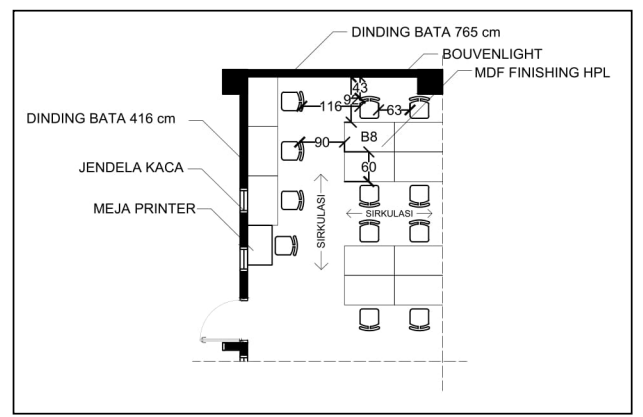

Gambar 12. Setting interior ruang kerja Redaktur Jawa Barat (B8) (Sumber: Data Pribadi, 2018) 


\section{Asisten Redaktur Opini (B9)}

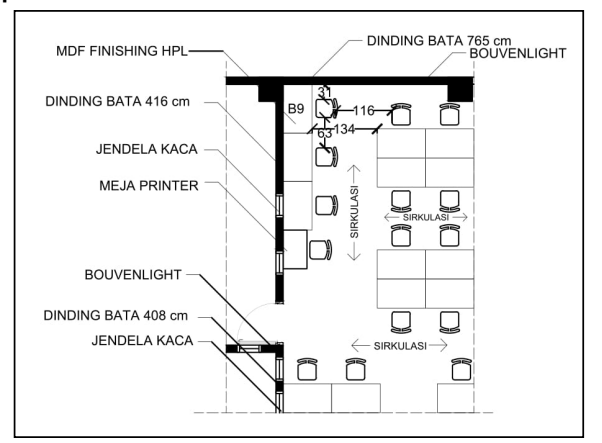

Gambar 13. Setting interior ruang kerja Asisten Redaktur Opini (B9)

(Sumber: Data Pribadi, 2018)

10. Redaktur Opini (B10)

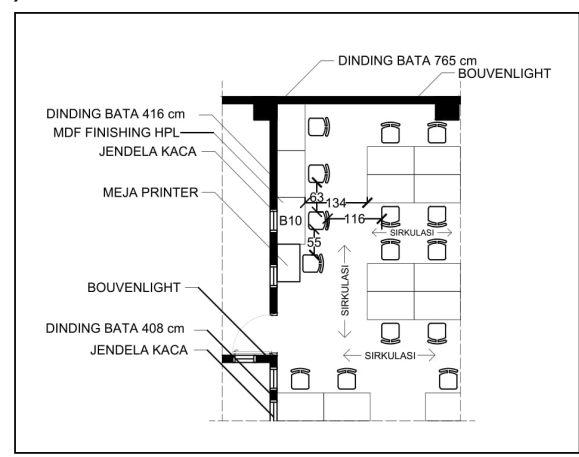

Gambar 14. Setting interior ruang kerja Redaktur Opini (B10)

(Sumber: Data Pribadi, 2018)

11. Wartawan Khazanah (B11)

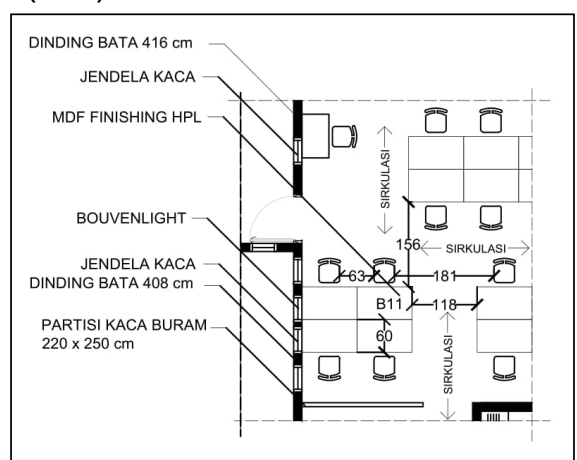

Gambar 15. Setting interior ruang kerja Wartawan Khazanah (B11) (Sumber: Data Pribadi, 2018)

\section{Hasil dan Temuan Penelitian}

Pada tabel 1 berikut menunjukkan data penilaian subjek penelitian terhadap privasi visual yang mereka rasakan saat ini. Adapun privasi visual yang dinilai menyangkut tatap muka, pekerjaan pada monitor, dan gangguan lingkungan sekitar seperti telah dijelaskan pada metode penelitian. 
Serat Rupa Journal of Design, July 2019, Vol.3, No.2: 134-149

E-ISSN: 2477-586X, ISSN: 2338-3348 | https://doi.org/10.28932/srjd.v3i2.1192 | Received: 09-01-2019, Accepted: 25-07-2019 Hafizha Azka, Yunita Setyoningrum, Ferlina Sugata

Preferensi Visual Pada Ruang Kerja Tim Redaksi Kantor Pusat Surat Kabar Pikiran Rakyat Bandung

Tabel 1. Kondisi tingkat gangguan privasi visual pada responden

\begin{tabular}{|l|c|c|c|}
\hline & $\begin{array}{c}\text { Tatap } \\
\text { Muka }\end{array}$ & $\begin{array}{c}\text { Pekerjaan } \\
\text { (monitor) }\end{array}$ & $\begin{array}{c}\text { Gangguan } \\
\text { Lingkungan }\end{array}$ \\
\hline B1 & & & \\
\hline B2 & & & \\
\hline B3 & & & $*$ \\
\hline B4 & & & $*$ \\
\hline B5 & $*$ & $*$ & \\
\hline B6 & & & \\
\hline B7 & & & \\
\hline B8 & & $*$ & $*$ \\
\hline B9 & $*$ & & \\
\hline B10 & & & $*$ \\
\hline B11 & $*$ & $*$ & $*$ \\
\hline
\end{tabular}

Keterangan tabel: Tanda $(*)$ : yang mengalami gangguan

(Sumber: dokumentasi pribadi, 2018)

\section{Analisis Privasi Visual di Ruang Kantor Terbuka}

a. Aspek Privasi Visual Tatap Muka

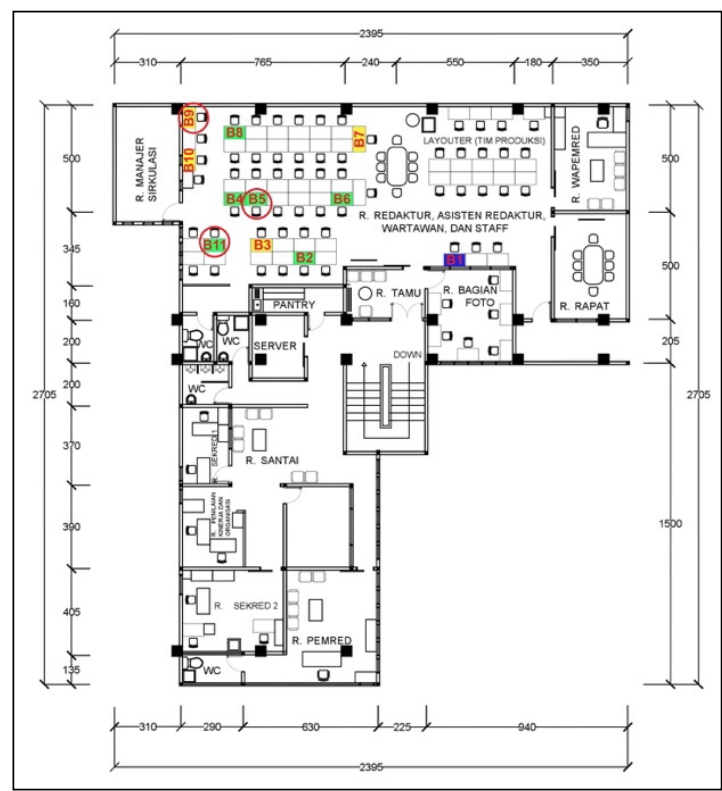

Gambar 16. Aspek Preferensi Privasi Visual Tatap Muka (Sumber: Data Pribadi, 2018)

Karyawan yang merasa terganggu dalam privasi visual tatap muka dalam ruang kantor terbuka adalah karyawan Redaktur Bandung Raya (B5), Asisten Redaktur Opini (B9) dan Wartawan Khazanah (B11). Berdasarkan hasil observasi dan temuan kuesioner, faktor penyebab terganggunya karyawan dalam tatap muka di ruang kantor terbuka yang paling dominan karena kondisi setting interior ruang kerja karyawan berdekatan dengan rekan kerja baik di samping kanan maupun di samping kiri. Selain itu, terdapat faktor penyebab lain yaitu karena kondisi setting interior ruang kerja yang berhadapan dengan rekan kerja 
namun tidak terlalu mengganggu (lihat gambar 9;13;15). Kondisi ini sesuai dengan aspek privasi visual terlihat oleh rekan kerja dan melihat rekan kerja di kantor (Goodrich, 1982). Oleh karena itu, agar wajah karyawan tidak dapat terlihat ataupun dilihat oleh karyawan lain, dapat menggunakan suatu pembatas fisik untuk menutupi wajah saat sedang berada di ruang kerja masing-masing. Pembatas fisik ataupun suatu fitur semi-tetap (Semi-fixed features) merupakan elemen di dalam ruang yang dapat dipindah-pindahkan (Hall, 1996) serta berfungsi untuk memisahkan orang (sociofugal) (Osmond dalam Hall, 1996)

b. Aspek Privasi Visual Pekerjaan (Monitor)

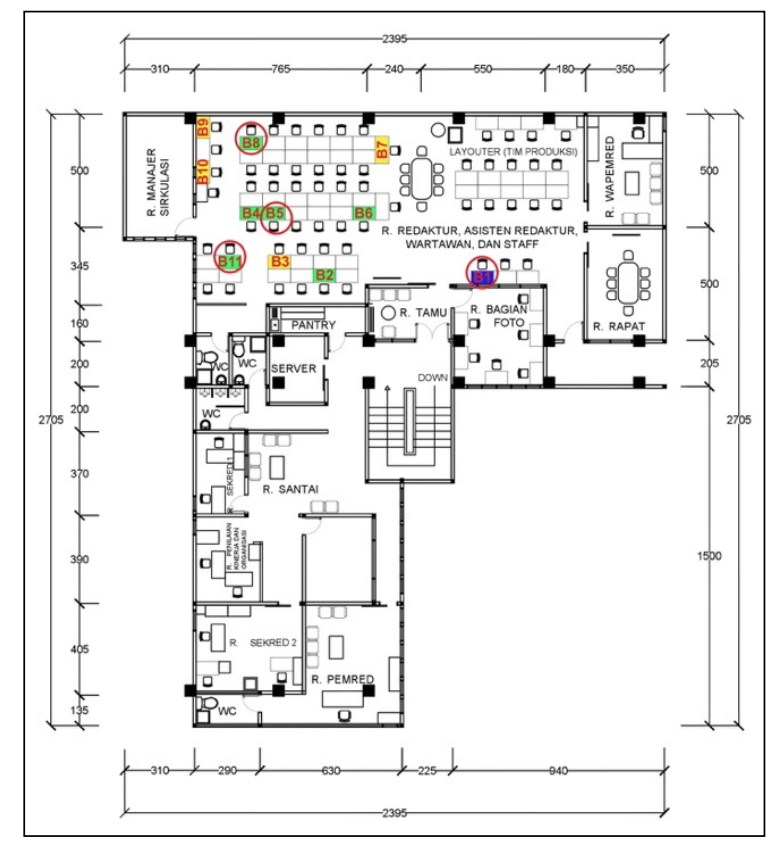

Gambar 17. Aspek preferensi privasi visual pekerjaan (monitor) (Sumber: Data Pribadi, 2018)

Karyawan yang merasa terganggu dalam privasi visual pekerjaan (monitor) dalam ruang kantor terbuka adalah karyawan Redaktur Pelaksana (B1), Redaktur Bandung Raya (B5), Redaktur Jawa Barat (B8), dan Wartawan Khazanah (B11). Berdasarkan hasil observasi dan temuan kuesioner, faktor penyebab terganggunya karyawan bila pekerjaan monitor dilihat oleh orang lain di ruang kantor terbuka yang paling dominan karena kondisi setting interior ruang kerja karyawan berada di persimpangan sirkulasi dan berdekatan dengan rekan kerja baik di samping kanan maupun di samping kiri (lihat gambar 5;9;12;15). Selain itu, terdapat 
Serat Rupa Journal of Design, July 2019, Vol.3, No.2: 134-149

E-ISSN: 2477-586X, ISSN: 2338-3348 | https://doi.org/10.28932/srjd.v3i2.1192 | Received: 09-01-2019, Accepted: 25-07-2019 Hafizha Azka, Yunita Setyoningrum, Ferlina Sugata

Preferensi Visual Pada Ruang Kerja Tim Redaksi Kantor Pusat Surat Kabar Pikiran Rakyat Bandung

faktor penyebab lain yaitu karena kondisi setting interior ruang kerja yang berada membelakangi sirkulasi namun tidak terlalu mengganggu. Kemudian, berdasarkan task list karyawan Redaktur Pelaksana (B1) memiliki tanggung jawab yang cukup besar untuk bagian redaktur yaitu bertugas untuk mengkoordinasi alur kerja para redaktur, perjalanan naskah dari awal hingga layout ke percetakan, proofing hasil layout sebelum cetak, membuat tajuk rencana, dan menilai kinerja bulanan. Kemudian karyawan Redaktur Bandung Raya (B5) dan Redaktur Jawa Barat (B8) memiliki tugas mengevaluasi berita lalu mencatat apa saja yang harus diliput oleh wartawan, evaluasi dan pengembangan hasil listing, budgeting halaman, pengeditan naskah yang sudah diberikan wartawan, kemudian layouting. Sedangkan untuk Wartawan Khazanah (B11), walaupun hanya di waktu tertentu saja berada di dalam kantor, namun tetap merasa terganggu karena memiliki tugas mengetik hasil liputan yang harus diberikan kepada redaktur dan membutuhkan ketelitian agar tidak ada berita yang terlewati. Hal ini termasuk dalam aspek karakteritsik kerja Signifikasi Tugas (Task Significance) yang pekerjaannya mempunyai dampak berarti bagi rekan kerja di dalam perusahaannya, Otonomi (autonomy) seberapa besar kebebasan yang dimiliki para pekerja dalam menjadwalkan dan mengatur pekerjaan mereka sendiri (Hackman \& Oldham, dalam Schultz \& Schultz dalam Roos, W., \& Van Eeden, R., 2008). Karakteristik kerja yang dimiliki keempat karyawan ini cenderung memiliki keinginan untuk menyendiri (solitude) (Holahan dalam Sarwono, 1992). Oleh karena itu, agar monitor di ruang kerja tidak dapat dilihat oleh karyawan atau orang lain, dapat menggunakan suatu pembatas fisik untuk menutupi monitor kerja saat sedang berada di ruang kerjanya masing-masing. Pembatas fisik ataupun suatu fitur semi-tetap (Semi-fixed features) merupakan elemen di dalam ruang yang dapat dipindah-pindahkan (Hall, 1996) serta berfungsi untuk memisahkan orang (Sociofugal) (Osmond dalam Hall, 1996) 
c. Aspek Privasi Visual Gangguan Lingkungan

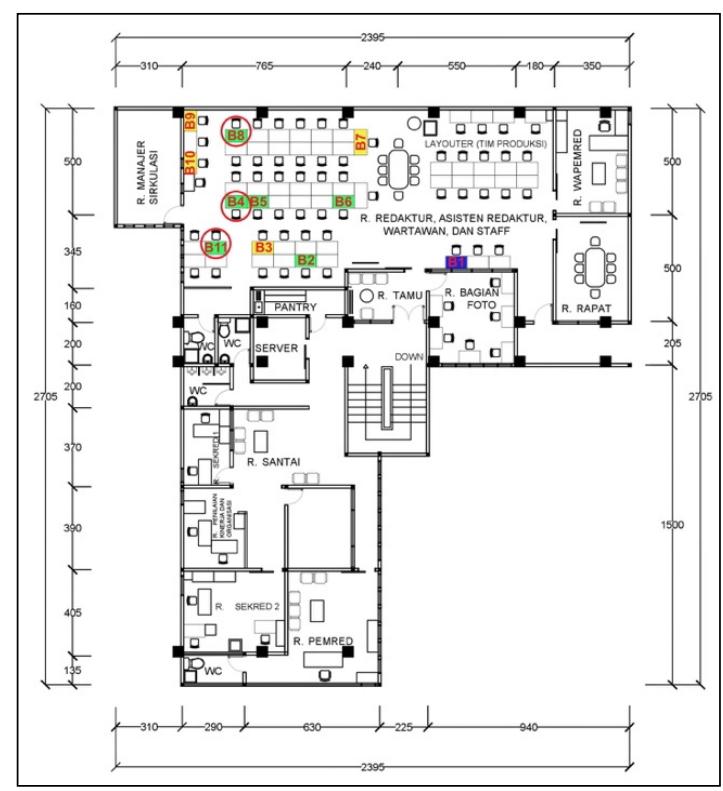

Gambar 18. Aspek preferensi privasi visual gangguan lingkungan (Sumber: Data Pribadi, 2018)

Karyawan yang merasa terganggu dalam privasi visual gangguan lingkungan dalam ruang kantor terbuka adalah karyawan Asisten Redaktur Dalam Negeri (B4), Redaktur Jawa Barat (B8), dan Wartawan Khazanah (B11). Berdasarkan hasil observasi dan temuan kuesioner, faktor penyebab terganggunya karyawan dalam lingkungan di ruang kantor terbuka yang paling dominan karena kondisi setting interior ruang kerja karyawan yang berhadapan dengan rekan kerja, dan berdekatan dengan rekan kerja baik samping kanan maupun di samping kiri. Selain itu, terdapat faktor penyebab lain yaitu karena kondisi setting interior ruang kerja yang berdekatan dengan fasilitas kerja bersama namun tidak terlalu mengganggu (lihat gambar 8;12;15). Kondisi ini sesuai dengan aspek privasi visual melihat rekan kerja bekerja, berlalu-lalang, hingga menyapa karyawan, dan menyebabkan terganggu secara visual (Kupritz, 1998). Sehingga karyawan cenderung memiliki keinginan untuk menjauh (seclusion) dari pandangan (Holahan dalam sarwono, 1992) untuk menghindari kesesakan (crowding) yang merupakan kegagalan memperoleh privasi karena kelebihan kontak sosial eksternal yang tidak diinginkan atau suatu proses interpersonal pada suatu tingkatan interaksi manusia satu dengan lainnya dalam suatu pasangan atau kelompok kecil (Altman dalam Edney \& Buda, 1976) Oleh karena itu, agar lingkungan tetap terjaga, dalam kantor terbuka ini dapat menggunakan suatu pembatas fisik untuk menutupi ruang kerja dari sekitarnya. Pembatas fisik ataupun suatu fitur semi-tetap (Semifixed features) merupakan elemen di dalam ruang yang dapat dipindah-pindahkan (Hall, 
Serat Rupa Journal of Design, July 2019, Vol.3, No.2: 134-149

E-ISSN: 2477-586X, ISSN: 2338-3348 | https://doi.org/10.28932/srjd.v3i2.1192 | Received: 09-01-2019, Accepted: 25-07-2019 Hafizha Azka, Yunita Setyoningrum, Ferlina Sugata

Preferensi Visual Pada Ruang Kerja Tim Redaksi Kantor Pusat Surat Kabar Pikiran Rakyat Bandung

1996) serta berfungsi untuk memisahkan orang (sociofugal) (Osmond dalam Hall, 1996) dibutuhkan jarak ruang personal yang merupakan jarak komunikasi dengan jarak antar individu ini merupakan jarak komunikasi juga antara 50-120 cm (Hall, 1966).

\section{PENUTUP}

\section{Simpulan}

Hasil penelitian menunjukkan bahwa 6 dari 11 karyawan yang dijadikan sampel pada ruang kantor terbuka merasa privasi visualnya terganggu karena kondisi setting interior ruang kerja yang digunakannya. Dengan tingkatan yang berbeda, para karyawan tersebut merasa privasi visualnya terganggu karena kondisi setting interior ruang kerja yang berdekatan dengan rekan kerja baik di samping kanan maupun di samping kiri. Setting interior ruang kerja yang berdekatan dengan rekan kerja baik di samping kanan maupun di samping kiri dengan tidak adanya pembatas fisik pada ruang kerja menyebabkan terlihatnya karyawan oleh rekan kerja dan melihat rekan kerja di kantor, terganggunya karyawan bila pekerjaan dalam monitor dilihat oleh orang lain, dan terganggunya karyawan melihat rekan kerja bekerja, berlalu-lalang, hingga menyapa karyawan serta menyebabkan gangguan secara visual. Namun, terdapat penyebab lain yang mengganggu yaitu setting interior ruang kerja yang berhadapan dengan rekan kerja, berada di persimpangan sirkulasi, berada membelakangi sirkulasi, dan berdekatan dengan fasilitas kerja bersama namun hal tersebut tidak terlalu mengganggu. Ada pula setting interior ruang kerja yang berbatasan langsung dengan pintu, namun hal tersebut sama sekali tidak mengganggu. Selain karena kondisi setting interior ruang kerja, deskripsi pekerjaan dan task list yang dimiliki karyawan pun mempengaruhi, pekerjaan yang membutuhkan ketelitian karena adanya tugas untuk mengkoordinasi alur kerja para redaktur, mengevaluasi berita, melakukan riset, pengeditan naskah, dan tugas-tugas lainnya yang berkaitan dengan persiapan naskah berita yang baik dan benar untuk setiap halamannya hingga siap cetak, sehingga karyawan cenderung memiliki keinginan untuk menyendiri (solitude). Hal tersebut berpengaruh pada aspek privasi visual dalam pekerjaan (monitor). Berbagai macam setting interior ruang kerja dan karakteristik pekerjaan karyawan tim redaksi dalam ruang kantor terbuka menyebabkan terjadinya kontak sosial yang berlebihan dan gangguan yang tidak terkendali karena berdekatan dengan orang lain serta kehilangan privasi yang dirasakan, yang biasa dikenal dengan overstimulation. 
Serat Rupa Journal of Design, July 2019, Vol.3, No.2: 134-149

E-ISSN: 2477-586X, ISSN: 2338-3348 | https://doi.org/10.28932/srjd.v3i2.1192 | Received: 09-01-2019, Accepted: 25-07-2019 Hafizha Azka, Yunita Setyoningrum, Ferlina Sugata

Preferensi Visual Pada Ruang Kerja Tim Redaksi Kantor Pusat Surat Kabar Pikiran Rakyat Bandung

\section{Saran}

Saran untuk ruang kantor terbuka tim redaksi di kantor pusat Pikiran Rakyat di antaranya adalah: (1) Luas ruangan pada ruang kantor terbuka yang digunakan tim redaksi di kantor pusat idealnya hanya bisa digunakan untuk 32 ruang kerja dengan posisi ruang kerja yang miring namun tetap berhadapan-hadapan, adanya pembatas fisik pada ruang kerja di bagian depan, samping kanan dan kiri dengan ketinggian sekitar 5 kaki (sekitar $152 \mathrm{~cm}$ dari permukaan lantai), dan sirkulasi antar ruang kerja minimal $120 \mathrm{~cm}$ (ruang sosial); (2) Pengadaan fasilitas kerja bersama berupa 1 meja tambahan untuk kebutuhan print; (3) Pengadaan ruang kosong yang digunakan sebagai ruang rapat redaktur dilengkapi dengan 2 lemari arsip untuk para redaktur, asisten redaktur, wartawan dan staf lainnya, dan papan tulis untuk rapat, serta ruang kecil yang difungsikan sebagai tempat penyimpanan barang karyawan tim redaksi maupun tim produksi seperti jaket, helm, dan barang-barang lainnya. Oleh karena itu, saran untuk ruang tim redaksi di kantor pusat Pikiran Rakyat adalah penambahan ruang untuk karyawan terutama untuk para karyawan redaktur, asisten redaktur, wartawan, dan staf lainnya agar memenuhi kebutuhan setiap masing-masing karyawan dalam lingkungan kerjanya seperti pada Gambar 19 berikut:

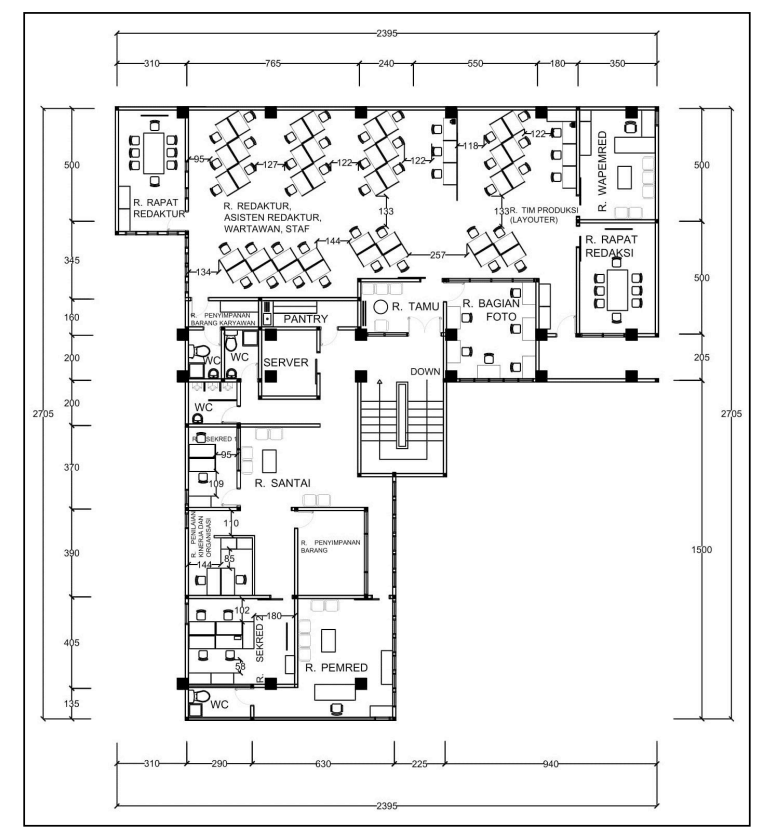

Gambar 19. Saran Tata Ruang Kantor Terbuka (Sumber: Data Pribadi, 2018)

\section{DAFTAR PUSTAKA}

Danielsson, C. B., \& Bodin, L. (2009). Difference in Satisfaction With Office Environment Among Employees in Different Office Types. Journal of Architectural and Planning Research, 26(3), 241-257. Retrieved from https://www.jstor.org/stable/43030872 
Serat Rupa Journal of Design, July 2019, Vol.3, No.2: 134-149

E-ISSN: 2477-586X, ISSN: 2338-3348 | https://doi.org/10.28932/srjd.v3i2.1192 | Received: 09-01-2019, Accepted: 25-07-2019 Hafizha Azka, Yunita Setyoningrum, Ferlina Sugata

Preferensi Visual Pada Ruang Kerja Tim Redaksi Kantor Pusat Surat Kabar Pikiran Rakyat Bandung

Edney, J. J., \& Buda, M. A. (1976). Distinguishing Territoriality and Privacy: Two Studies. Human Ecology, 4(4), 283-296. Retrieved from https://www.jstor.org/stable/4602378

Goodrich, Ronald. (1982). Seven Office Evaluation: A Review. Environment and Behavior 14(3). 353-378. Sage Publication Inc.Gregory, J. R., \& Wiechmann, J. G. (1999). Marketing Corporate Image: The Company as Your Number One Product. McGraw Hill Professional.

Hall, E. T. (1966). The hidden dimension, 1st ed. New York, NY, US: Doubleday \& Co.

Johnson, B. (n.d.). (2017). Optimizing the Workplace for Innovation: Using Brain Science for Smart Design. diunduh dari https://www.officeimagesinc.com/wpcontent/uploads/2017/11/Innovation-White-Paper_Haworth.pdf

Kim, J., \& de Dear, R. (2013). Workspace satisfaction: The privacy-communication trade-off in open-plan offices. Journal of Environmental Psychology, 36, 18-26. https://doi.org/10.1016/j.jenvp.2013.06.007

Laurens, J. M. (2006). Arstitektur dan perilaku manusia. Grasindo.

Rizza, C., Curvelo, P., Crespo, I., Chiaramello, M., Ghezzi, A., \& Pereira, Â. G. (n.d.). (2011). Interrogating Privacy in the digital society: Media narratives after 2 cases. International Review of information ethic. 16(12). Diunduh dari http://www.i-r-ie.net/inhalt/016/rizza-etal.pdf.

Roos, W., \& Van Eeden, R. (2008). The relationship between employee motivation, job satisfaction and corporate culture. SA Journal of Industrial Psychology, 34(1). doi:10.4102/sajip.v34i1.420

Sarwono, S. W. (1992). Psikologi lingkungan. Grasindo.

Sundstrom, E., Burt, R. E., \& Kamp, D. (1980). Privacy at Work: Architectural Correlates of Job Satisfaction and Job Performance. The Academy of Management Journal, 23(1), 101117. https://doi.org/10.2307/255498

Zavani, M. N., \& Rahardjo, S. (2016). Pengaruh Setting Elemen Fisik Ruang Kantor Terhadap Produktivitas Kerja Karyawan. (Studi Kasus: Kantor Redaksi Harian Umum Pikiran Rakyat, Bandung). Idealog: Ide Dan Dialog Desain Indonesia, 1(1), 34-36. https://doi.org/10.25124/idealog.v1i1.840 